\title{
Reflexiones filosóficas y psicoanalíticas en la era del discurso capitalista*
}

\author{
José Antonio Vergara Costas*
}

Recibido: 7 de julio de 2016 - Aprobado: 14 de septiembre de 2016

\section{Resumen}

El pensar filosófico, junto con el saber analítico, crean un nuevo espacio de observación. El discurso capitalista y sus tentativas socializadoras han transformado los espacios sociales y han alejado al sujeto freudiano de una interacción fluida con el otro. El discurso y su 'nueva era' marca la desintegración de espacios fundamentales en la estructura social del sujeto. La alteración del espacio tiempo del individuo, el enclaustramiento en el mero acto del consumo y la vivencia en una estructura social marcada por el goce son algunos de los elementos presentes en la actual socialización.

La hipótesis del presente artículo se fundamenta en el pensar reflexivo sobre la actual socialización del sujeto: ¿nos encontramos frente a una nueva manera de relacionarnos con el otro?, ¿hemos perdido la capacidad de relacionarnos entre nosotros?, ¿nos enfrentamos a una socialización marcada por y para el objeto olvidando un rasgo tan humano como la reflexión y el saber como consecuencia del estar en el mundo? La respuesta a estas preguntas nos obliga a una amplia reflexión sobre el sujeto y sus implicaciones psicoanalíticas; el discurso capitalista y sus nuevas formas de vínculo social, el sujeto y su entorno social, así como el rol que en el interior de este discurso toma el objeto mercancía. El tiempo será otro objeto de análisis: el olvido del pasado como fuente de entendimiento y reflexión, el presente como un continuo y el futuro como una proyección del entendimiento del sujeto. La profundización en este pensar filosófico nos dirige a Jacques Lacan y su teorización del espacio social, su enseñanza de los discursos como forma de lazo social, sus implicaciones en la vida del individuo, el goce como forma de transgresión que permite dar una explicación reflexiva en torno al desarrollo social capitalista.

Palabras clave: discurso capitalista, tiempo, socialización, objeto consumo, goce, plenitud, vacío.

Artículo de reflexión que nace del trabajo desarrollado con el grupo de investigación Filosofía Aplicada: Sujeto, Sufrimiento Sociedad. Universidad de Sevilla, España. DOI: http://dx.doi.org/10.15332/s0120-8454.2016.0090.08

\footnotetext{
Doctor en filosofía Universidad del País Vasco (UPV), Euskal Herriko Unibersitatea (EHU). Miembro del grupo de investigación Filosofía Aplicada: Sujeto, Sufrimiento, Sociedad. Universidad de Sevilla, España. Dirección postal: Pedro Egaña 2, 2 izquierda 20006, San Sebastian/Donostia, Gipuzkoa, España. Correo electrónico: javergaracostas@hotmail.com
} 


\title{
Philosophical and psychoanalytic reflections in the era of capitalist discourse*
}

\author{
José Antonio Vergara Costas**
}

\section{Abstract}

Philosophical thinking, in combination with analytical knowledge, creates a new space for observation and reflection. The discourse on capitalism and its socializing attempts have transformed social spaces in a manner that distances the freudian subject from a smooth interaction with the other. The discourse and its 'new era' mark the disintegration of fundamental areas in the social structure of the subject. The alteration of the space-time of the individual, the confinement in the mere act of consumerism and living in a social structure marked by jouissance are some of the elements currently present in socialization.

The hypothesis of the present article is based on reflective thinking about the subject's socialization in the present age: Are we faced with a new way of relating to the other? Have we lost the ability to interact with each other? Are we confronted with a manner of socialization defined by the object of consumption, thus forgetting fundamentally human traits such as reflection and knowledge as a result of being-in-the-world? The study of these issues forces us to broadly reflect on the subject and its psychoanalytical implications, on the discourse of capitalism and its new social bonds that affect the subject and its social environment, as well as on the role that is assigned to the object of consumption within this discourse. Time is another topic of philosophical analysis: the act of forgetting the past as a source of understanding and reflection, the present as a continuum and the future as a projection of the former understanding of the subject. This profound philosophical thinking leads us to Jacques Lacan and his theories regarding social space, to his teaching of discourses as a form of social bond, their implications for individual's life, jouissance as a form of transgression that provides a reflective explanation around the capitalist social development.

Keywords: Discourse of capitalism, time, socialization, object of consumption, jouissance, plenitude, void.

Reflection article resulting from the work developed with the research group Applied Philosophy: Individual, Suffering, Society. University of Seville, Spain. DOI: http://dx.doi.org/10.15332/s0120-8454.2017.0090.06

* PhD of Philosophy UPV/EHU. Member of the research group Applied Philosophy: Individual, Suffering, Society. University of Seville, Spain. Postal address: Pedro Egaña 2, 2 izquierda 20006, San Sebastian / Donostia, Gipuzkoa, Spain. Email: javergaracostas@hotmail.com 


\title{
Réflexions philosophiques et psychanalytiques à l'ère du discours capitaliste*
}

\author{
José Antonio Vergara Costas*
}

\section{Résumé}

La pensée philosophique et la connaissance analytique créent un nouvel espace d'observation. Le discours capitaliste et ses tentatives de socialisation ont transformés les espaces sociaux et ont éloignés le sujet freudien d'une bonne interaction avec l'autre. Le discours et sa «nouvelle ère» marque la désintégration de domaines clés dans la structure sociale du sujet. L'altération de l'espace-temps de l'individu, son confinement dans le simple acte de la consommation et la vie dans une structure sociale marquée par la jouissance sont quelques-uns des éléments présents dans l'actuelle socialisation.

L'hypothèse de cet article se base sur la pensée réflexive à propos de l'actuelle socialisation du sujet: sommes nous face à un nouveau mode de relation avec l'autre?, avons-nous perdu l'aptitude de socialiser entre nous ?, sommes-nous confrontés à une socialisation marquée par et pour l'objet, oubliant un trait tellement humain comme la réflexion et la connaissance comme conséquence d'être dans le monde? La réponse à ces questions nous oblige à une ample réflexion sur le sujet et ses implications psychanalytiques; le discours capitaliste et ses nouvelles formes de lien social, le sujet et son environnement social, ainsi que le rôle qui à l'intérieur de ce discours prend l'objet marchandise. Le temps fera l'objet d'une autre analyse: l'oubli du passé comme source de compréhension et de réflexion, le présent comme une continuation et l'avenir comme une projection de la compréhension du sujet. L'approfondissement dans cette pensée philosophique nous dirige à Jacques Lacan et sa théorisation de l'espace social, son enseignement des discours comme forme de lien social, ses implications dans la vie de l'individu, la jouissance comme forme de transgression qui permet de donner une explication réflexive autour du développement social capitaliste.

Mots clés: Anthropologie, mystique, Saint Jean de la Croix, âme, homme, Dieu.

Article de réflexion qui naît du travail développé avec le groupe de recherche Philosophie Appliquée: Sujet, Souffrance, Société. Université de Séville, Espagne. DOI: http://dx.doi.org/10.15332/s0120-8454.2017.0090.06

\footnotetext{
Docteur en Philosophie. Membre du groupe de recherche Philosophie Appliquée: Sujet, Souffrance, Société. Université de Séville, Espagne. Adresse postale: Pedro Egaña 2, 2 izquierda 20006, San Sebastian/Donostia, Gipuzkoa, España. Email: javergaracostas@hotmail.com
} 
La necesidad de dejar que hable su elocuencia al dolor es la condición de toda verdad. $Y$ es que el sufrimiento es objetividad que pesa sobre el sujeto; lo que este experimenta como lo más subjetivo, su propia expresión, está mediado objetivamente.

Theodor W. Adorno.

Lacan, a partir de la dialéctica amo y esclavo de Hegel, elabora su teoría de los discursos e identifica cuatro tipos de vínculo social, cuatro articulaciones, cuatro elementos que organizan las relaciones intersubjetivas; estos cuatro discursos son el discurso del amo, el discurso universitario, el discurso de la histérica y el discurso del analista. Jacques Lacan crea el discurso capitalista dos años después de los incidentes de mayo de 1968, su conceptualización y desarrollo se aleja del concepto marxista de capitalismo. Lacan recoge su teorización de los discursos como modalidades de lazo social, es decir, las relaciones entre los seres humanos y las modalidades que dicho lazo tiene como una regulación de los goces. Esta regulación es imprescindible para que un lazo sea posible. Lacan y su noción de discurso implica que no solo el inconsciente se estructura como un lenguaje, sino también la realidad que nos rodea: la realidad del mundo se estructura vía el lenguaje. El discurso puede entenderse como la organización de la comunicación, principalmente del lenguaje y las relaciones del sujeto con los significantes y el objeto, siendo determinantes para el individuo y para la sistematización del lazo social.

El discurso capitalista plantea una paradoja en relación con el resto de los discursos. Lacan define los discursos como tipos de lazo social, desarrollando el discurso capitalista que deshace los lazos sociales: "La palabra que Lacan usa en el año 70 es 'fragmentación'. Fragmentación de los lazos sociales" (Soler, 2007, pp. 135-136). El discurso hace pasar a la realidad una adaptación del fantasma ${ }^{1}$. Este fantasma en el discurso capitalista está marcado por el objeto y su plenitud: el lazo directo de un sujeto con un objeto, que no es el objeto individual que ordena el discurso de cada sujeto, sino que es un objeto ordenado por todo el discurso e idéntico para todos los sujetos (objeto consumo). Esto es lo que da el efecto de homogeneización del discurso capitalista.

El discurso capitalista en el contexto social muestra las graves alteraciones de una vida carente de límites. Todas aquellas conductas y actuaciones en las que el goce excesivo se expone en lo cotidiano nos enseña el predominio de las llamadas patologías del acto. Dichos modelos tienden a ser capturados por políticas de consumo, los cuales exacerban al individuo egocéntrico en detrimento de la solidaridad y el altruismo. El discurso capitalista nos instala en la incapacidad de modificar la política del imperativo, las amenazas económicas y

1 En la teorización lacaniana, el fantasma se entiende como lo que permite al sujeto sostener su deseo y también aquello por lo cual el sujeto se sostiene a sí mismo. Lacan reconoce el poder de la imagen en el fantasma, pero insiste en que no se debe a una cualidad intrínseca de la imagen en sí, sino al lugar que ocupa en una estructura simbólica; la estructura es siempre "una imagen puesta a trabajar en una estructura significante" (Lacan, 2007, p. 272). 
el descontento social no logran penetrar los espacios de socialización. El narcisismo actual es fruto del discurso capitalista, no una nueva versión del divertirse. Este narcisismo capitalista ha abolido lo crítico, presentándose como una forma inédita de apatía. El narcisismo capitalista nace del abandono generalizado de los valores y finalidades sociales, impulsando un proceso de renuncia de los grandes sistemas de sentido y del desarrollo comunitario en el espacio social del sujeto. Dichos sistemas de rostro humano funcionan por y para el bienestar, promocionando el individualismo puro, liberándose de los encuadres de masas y enfocándose en la valoración de una individualidad colectivizada. La revolución de las necesidades y su ética hedonista fragmenta a los individuos vaciando las finalidades sociales de su significado, permitiendo que la narrativa capitalista se inserte en lo social convirtiéndose en un nuevo ethos (cultura). El materialismo exacerbado y la sociedad de la abundancia ha posibilitado la aparición de una cultura sin límites basada en el imperativo de goce. Este goce ha infiltrado los discursos sociales, defendiendo una concepción perversa de la realidad en la cual se tiende a abolir el reconocimiento de la alteridad.

El padre despótico y autoritario reseñado por Freud, en Tótem y Tabú (1913) ,conduce a los individuos hacia su contrapartida. La falta de normas del discurso capitalista encarna el todo vale del imperativo de goce, justificando la complicidad transgresora de un hedonismo a ultranza que se instituye en valor. La presencia de un discurso inductor del acto y cómplice en el desafío a la ley incrementan la realidad del imperativo. El sujeto no encuentra la sanción simbólica, perpetuando su malestar en la transgresión, extinguiendo todo cuestionamiento de su entorno, cayendo en un delirio estructurado del discurso del consumo.

El goce es una de las grandes preocupaciones de la teoría lacaniana, a su vez es imprescindible su utilización como herramienta de análisis del discurso capitalista. La conceptualización de goce se distingue del uso común del término que lo sitúa como un sinónimo de placer en general y del sexual en particular.

El goce lacaniano y las conceptualizaciones freudianas nos remiten al Más allá del principio del placer (1920). Lacan plantea el goce en su relación con el sujeto, el cual es deseante por su vínculo con la palabra y el lenguaje: el que goza es el hablante-ser (parlétre). El goce completo es imposible de escribir, en su lugar se escriben funciones destinadas a recuperar algo de goce a partir del lenguaje. Este goce articulado al deseo y al lenguaje está marcado por la falta y no por la plenitud del ser.

Los goces son parciales, aunque el hablante-ser aspire a totalizarlos. La zona central del nudo que aloja el objeto a, es un punto vacío que conduce indefectiblemente a que exista un desfase entre el goce esperado y el goce alcanzado; en síntesis, no hay goce absoluto. (Korman, 2004, p. 345)

El principio del placer actúa como un límite al goce. Una ley que le ordena al sujeto gozar lo menos posible. El sujeto desea transgredir constantemente las 
prohibiciones impuestas a su goce, ir más allá del principio del placer, el resultado de traspasar el principio del placer no es más placer sino dolor. El sujeto solo puede tolerar una cierta cantidad de placer, más allá de ese límite el placer se convierte en dolor, este placer doloroso es lo que Lacan denomina goce.

La reflexión del goce en El seminario 17. El reverso del psicoanálisis (1969-1970) marca el interés de Lacan por los procesos culturales y sugiere la intervención en lo político, si se reconoce que no hay discurso que no sea del goce: "Si el saber es medio de goce, el trabajo es otra cosa. Incluso si lo realizan quienes poseen el saber" (Lacan, 2009, p. 84).

El discurso capitalista en este contexto de goce y trasgresión estandariza el espacio social, encerrando al individuo en el interior de un claustro productivo, socializándolo a través de la vorágine del consumo, exiliándolo de su saber y de su capacidad crítica, transformándolo en un misántropo de la cultura. Esta nueva identidad capitalista marcada por el goce sin límites y la trasgresión absoluta rompe con la identidad individual. El discurso presenta al hombre como un ser genérico, sin relación alguna con el otro, cada uno es aquello en virtud de lo cual puede ser sustituido por otro: fungible, un ejemplar. El individuo es lo absolutamente sustituible, un engranaje de la máquina capitalista.

El individuo sumergido en lo más espeso del discurso asocia en forma errónea sus peculiares modos de progreso, hundiéndose en la mecánica de la tecnología y en el más voraz de los consumos. La consciencia del individuo está cercenada entre la búsqueda del objeto mercancía y la mecanización productiva.

La acumulación de objetos, en su origen, se mantenía desvinculada a toda naturaleza del hombre. El desarrollo de la técnica, en su génesis estuvo centrado en la supervivencia y no en la acumulación de bienes. Los diversos intereses y propósitos humanos, así como sus diferentes necesidades orgánicas, restringían el crecimiento excesivo de sus componentes aislado, de ahí en adelante, el principal interés del individuo consistió en su autotransformación, lo que alcanzó a grupo tras grupo, aldea tras aldea, región tras región. Esta metamorfosis esclavizó al hombre, condenando al individuo a una búsqueda delirante de objetos que taponen y hagan olvidar su falta.

El individuo, en el interior del discurso capitalista, se socializa en los objetos, una estructura que comprime el deseo de saber sobre su propia falta. Lacan estructura la falta como una falta de ser, que no es la falta de esto o aquello, sino la falta de ser por la cual el ser existe. La falta es la condición del ser hablante (pậrletre), que lo hace depender de un déficit o de una incompletud tan necesaria como inadvertida en todo lo que se presenta para el sujeto como un todo: "Un hecho contradice esta calificación, y es que se reconozcan en ella no mitos auténticos, los cuales sin falta dejan siempre legible la incompletud del sujeto" (Lacan, 2007, p. 223). 
El objeto y su conceptualización marcan nuevas cualidades (plenitud, felicidad). El discurso capitalista, en sus espacios de producción, fabrica artículos para ser consumidos por las masas. Adorno, en Crítica de la cultura y sociedad (1969), desarrolla la idea de industria cultural, planteando la transformación de obras de arte en objetos al servicio de la comodidad. El autor recoge dicha idea y establece un paralelo con el objeto en el interior del discurso capitalista.

[...] la industria cultural especula con el estado de la consciencia e inconsciencia de los millones a los que dirige, las masas no son lo primario, sino algo secundario, incluido en el cálculo; un apéndice de la maquinaria. Al contrario de lo que la industria cultural intenta hacernos creer, el cliente no manda, no es sujeto, sino un objeto. (Adorno, 2008, p. 296)

Mientras Adorno plantea la transformación de la obra de arte, el discurso capitalista diseña el objeto como tapón de la falta estructural del sujeto. El objeto, en el interior de la ficción capitalista, se presenta análogo al objeto perdido definido por Freud (1915). El objeto desconoce aquella pérdida en el origen, en la estructura misma del sujeto: un acto de poder, un acto de exclusión, lo que retroactivamente produce la supuesta plenitud que atribuimos al objeto. Freud en su obra Tótem y Tabú (1913), desarrolla la figura del padre de la horda primitiva, figura mítica mitad hombre mitad bestia que poseía el poder absoluto y sin restricciones en la satisfacción de su deseo. El sujeto contemporáneo busca esa libre satisfacción del padre de la horda, desconociendo el pacto social que funda la cultura y pone límite al goce. Esta trasgresión marcada por la imposibilidad hace entrar al sujeto en la ilusión del objeto mercancía, dejando libre y sin límite a la ficción financiera del discurso.

La identificación del yo del sujeto y la sustitución del ideal del Yo por el objeto mercancía se descubre en el consumo ilimitado instaurado por el discurso capitalista. El individuo transforma al consumidor en su ideal, mientras se hermana con el resto de los individuos en su afán de consumo; esa relación permite una unificación a través del objeto. El discurso capitalista y su máquina publicitaria disemina la idea de comprar lo que se quiere ser, en otras palabras, promete la obtención del objeto $a^{2}$. La estructura del consumo y el discurso han sido capaces de definir las formas comerciales que pueden llegar a tomar nuestros deseos inconscientes. Esta cruzada capitalista marcada por el consumo y la diversidad de bienes diluye el saber del sujeto, en tanto el objeto a través de su plenitud disuelve la duda y el cuestionamiento. Todas las interrogantes se responden a través de la plenitud entregada por el objeto: su adquisición confiere

2 Lacan, en su seminario La transferencia (1960-1961) articula el objeto a con el término ágalma (una palabra griega que significa 'una gloria', 'un ornamento', 'una oferta a los dioses' o 'la pequeña estatua de un dios'), que toma de El banquete, de Platón. Así como el ágalma es un objeto precioso oculto en una caja relativamente carente de valor, el objeto a es el objeto del deseo que buscamos en el otro. El objeto a responde en este lugar de la verdad para el sujeto en todos los momentos de su existencia. En el nacimiento, en tanto el niño se presenta como el resto de una cópula. Antes de todo deseo, como el objeto guía alrededor del cual la pulsión gira y se satisface sin poder alcanzarlo. En la constitución del fantasma, verdadero acto de nacimiento del sujeto del deseo, como el objeto cedido como precio de la existencia. En la experiencia amorosa, como esa falta que el objeto amado envuelve o esconde. 
la totalidad y la plenitud. El sujeto se siente completo y en aquella plenitud no existe espacio para la duda y el cuestionamiento. El objeto mercancía le entrega el todo (plenitud), mientras el instinto de saber se disuelve en la plenitud del objeto. El objeto = plenitud que entrega el discurso capitalista otorga certezas no dudas. La totalidad y la plenitud desconocen el cuestionamiento, la duda y la pregunta, omitiendo las incertidumbres e interrogantes, que son la esencia del animal pensante, que es el parlêtre.

El éxito del consumo fuente de placer e identidad no puede explicarse solo por el desarrollo tecnológico y económico. El psicoanálisis apunta a que el placer provocado por el consumo se articula con la destrucción y homogenización de fuentes de identidad provenientes del espacio social. El discurso capitalista supone el imperativo de goce, el cual extingue los límites del sujeto estructurando desde el consumo el imperativo "igoza!", "iconsume!": un espacio cosificado rodeada por márgenes rígidos, carente de ideologías y cuyo fin último es fagocitar objetos. El discurso se constituye una manera de articular la tendencia de los individuos a la satisfacción sin límites. La prohibición es inexistente dentro del discurso, configurando la repetición del individuo en tanto búsqueda desesperada del más allá del principio del placer, cuyo resultado no es placer sino dolor. Este movimiento perverso lleva al individuo al desenfreno del consumo, amparado en el imperativo de goce (debes gozar-debes consumir) avanza hacia la transgresión utópica de un imposible, transformándose en un ser anestesiado donde la imagen de su cuerpo evoca un vacío vital, envuelto en el autismo social y en la socialización a través de los objetos.

Esta perspectiva radical que Lacan denuncia a través del discurso capitalista muestra las nuevas concepciones de colectividad, realidad y objetividad social. Todos los espejismos que capturan la imaginación social y guían la praxis política están marcados por la negación de nuestra falta constitutiva. Esta falta se localiza en el centro de la dialéctica entre lo subjetivo y lo objetivo. La fantasía capitalista se revela al individuo como una dialéctica de la negación de la imposibilidad. El discurso busca una identidad cerrada en su posibilidad, dando paso a una identificación con objetos mercancía, la negación de la falta en el nivel objetivo del sujeto implica que todas las identificaciones con los objetos reproducen la falta que el discurso desconoce.

Si necesito identificarme con algo es, no solo, y en primer término, porque no tengo una identidad completa, sino también porque todos mis intentos por adquirirla mediante la identificación con otro supuestamente completo resultan fallidos. La identificación se vuelve pensable solo como resultado de la falta dentro de la estructura, la estructura del otro social. Lo objetivo como una totalidad cerrada es una apariencia; el otro objetivado está atravesado por la falta. (Stavrakakis, 2007, p. 71) 
El discurso capitalista pervierte la Ley del Padre ${ }^{3}$, desarrollada por Lacan imponiendo la cultura del imperativo, transformándose en la transgresión al límite impuesto en la génesis de la cultura. La narrativa capitalista construye una nueva socialización, transgrediendo el goce en aras de una posición que ignora y desconoce al otro en su diferencia radical. La nueva socialización capitalista neutraliza el universo social, vaciando las instituciones de sus elementos emocionales, transformando al hombre en un ser vacío en su identidad. El espacio público se vacía emocionalmente por exceso de objetos. El sujeto pierde sus referencias y su unidad transformándose en un conjunto impreciso, logrando la desaparición de la realidad, instaurando la desnaturalización capitalista como forma de dirección de la modernidad.

Lewis Mumford desarrolla la idea de una megatécnica que, aplicada al discurso dominante, crea una estructura uniforme. Desde esta perspectiva, y recogiendo la idea de Foucault (1975), nos enfrentamos a una sociedad disciplinaria que, amparada en la modernidad capitalista, desarrolla tecnologías de control y nuevas construcciones de identidad. El poder de la razón capitalista no es una mera fuerza de represión, sino una posibilidad de realización y transformación. El discurso capitalista, al destruir el vínculo social, se transforma en la razón que ve, la razón que controla, la razón que domina. Esta razón instrumentalizada se encarna en el objeto consumo como una nueva herramienta de dominio y control. El poder impone la verdad a través del objeto mercancía ${ }^{4}$. El sujeto se transforma en un receptor de ese poder y verdad. La razón capitalista, como manifestación del poder imperante, se reduce a un juego de representaciones simbólicas que, en la ausencia de pensamiento crítico, envuelve al sujeto pasivo en la representación del discurso. Esta exclusión del sujeto crítico es aprovechada por la organización interna de las representaciones capitalistas. El objeto en la era del discurso se presenta como la negación de la humanidad del sujeto. El hombre es una instancia funcional en un juego de representaciones del saber sobre el objeto consumo.

El poder de la razón capitalista crea una verdad absoluta desde su interpretación de la realidad. El discurso capitalista tiene el poder de imponer su interpretación, imponer esa verdad a través de su retórica simbólica: lo que el discurso comunica es la verdad del poder. La interpretación que el poder del discurso tiene de los hechos y de los objetos están dirigidos a sujetar la consciencia del individuo: su meta es sujetar la subjetividad de los sujetos, conquistarla y hacerla suya. El individuo pierde su función como personalidad autónoma, olvidando toda capacidad crítica, transformándose en una máquina condicionada, limitada

3 Lacan, en su definición de ley, debe mucho a la obra de Claude Lévi-Strauss. La ley no es en Lacan un fragmento de legislación particular, sino los principios fundamentales que subyacen en todas las relaciones sociales. La ley es el conjunto de principios universales que hacen posible la existencia social, las estructuras que gobiernan todas las formas de intercambio social, sea el acto de regalar, las relaciones de parentesco o las formación de pactos. La forma básica de intercambio es la comunicación, por lo tanto, la ley es de manera fundamental una entidad lingüística: es la ley del significante. El padre será quien impone esta ley al sujeto en el complejo de Edipo; la agencia paterna no es más que el nombre de este papel prohibitivo y legislativo.

4 El autor del presente artículo no indica diferencias entre objeto consumo, objeto mercancía u objeto; todos los conceptos utilizados refieren al mismo elemento en tanto artículos materiales ofertados por el actual discurso capitalista. 
y controlada en provecho de organizaciones que diluyen sus posibilidades organizativas.

El diagnóstico de Nietzsche (1887) sobre la tendencia moderna a favorecer la debilidad de la voluntad imprime hoy toda su vigencia. La transgresión del consumo, los impulsos y las tendencias marcadas por el imperativo del goce marcan la vida del sujeto. El discurso de la acumulación y su culto al objeto mercancía han transformado los inventos de los primitivos logrados en el ritual, la organización social, el lenguaje y la moral, en reliquias materiales.

Los elementos materiales se asocian a una imagen de desarrollo y perfección del individuo haciendo olvidar la falta del sujeto, la cual no se llena con ningún tipo de materia. La trampa del discurso radica en reunir el poder disciplinando la falta del sujeto, pasando de la satisfacción de las necesidades ${ }^{5}$ a la falsa satisfacción del deseo ${ }^{6}$. Esta falsa promesa del discurso oculta el verdadero deseo del sujeto, haciendo posible la uniformización de la masa a través de la acumulación y la organización del trabajo. El individuo se enfrenta a una estructura que se retroalimenta en todos sus ámbitos. El discurso entrega los placebos (objetos consumo, objeto mercancía) a través de una producción organizada y estructurada de objetos: rápido consumo y desecho instantáneo, logrando por medio de este juego productivo una rápida reactivación de la cadena y una eternización de la estructura.

Los individuos se transforman en una masa viva a través de los objetos: un ente aislado y concentrado en la acumulación, sin ninguna relación con su sentido crítico. El trabajo organiza el nuevo colectivo ejerciendo modos de coerción y castigo, limitando los modos de desarrollo alternativo, encapsulando al individuo en un juego de premios tangibles. El discurso reduce el área de la autonomía comunal, de la iniciativa personal y de la autorregulación. La sustitución de todo límite y la identificación del Yo a un objeto marcado por la utopía de la plenitud se descubre en el consumo ilimitado instaurado por el discurso capitalista. El individuo transforma al consumidor en su ideal, mientras se hermana con el resto de sujetos en su afán de consumo, concluyendo de esta comunidad una unificación a través del objeto.

Este juego perverso lleva al individuo al desenfreno del consumo. El sujeto amparado en el imperativo de goce (debes gozar - debes consumir) avanza hacia una verdad marcada por la razón capitalista. El discurso ofrece esa plenitud ilusoria y común para todos los individuos, logrando su adormecimiento a través del olvido de su propio malestar. La ilusión de llenar la falta del sujeto anula su deseo: al sujeto no le falta nada, no hay deseo, solo goce. Esta nueva razón

5 Lacan, en 1958, desarrolla una distinción entre los conceptos de necesidad, demanda y deseo. Necesidad será la conceptualización que más se acerca a lo que Freud denomina instinto (instintk), en otras palabras, un concepto biológico opuesto al reino de la pulsión (trieb).

6 En su definición de deseo, Lacan no se refiere a cualquier clase de deseo, sino que siempre está dirigido al deseo inconsciente. Esto no significa que el deseo consciente carezca de importancia, sino que solo es posible reconocer el deseo propio cuando se lo articula en la palabra. El deseo es esencialmente deseo del deseo del Otro, lo que significa deseo de ser objeto de deseo del otro. 
capitalista alcanza todas las esferas del individuo. El sufrimiento, la frustración y el propio malestar son normalizados: esta renuncia persigue la neutralización de lo 'anormal'. Las conductas que conducen a la diferencia son regladas por el discurso, la oposición es controlada en su inclusión en la estructura del poder capitalista. El síntoma del malestar social olvida su origen, permitiendo al espacio capitalista absorber el descontento adaptando la diversidad y transformándola en norma. Michel Foucault, en su libro La historia de la locura en la época clásica (1967), lo expone con claridad. El momento del encierro rompe con la percepción más fina de la figura del loco en el renacimiento. Su invisibilización transforma al demente en una masa compacta arrojada al hospital general. Foucault desarrolla con la locura aquello que el discurso capitalista expone en la normalización de una nueva socialización carente de vínculo social. El objeto anuda al sujeto con el discurso, imposibilitando todo vínculo que pretenda prescindir de la dialéctica discurso/objeto.

El discurso actual no es más que un empuje al goce sin barreras, un plus-degoce reabsorbido y reciclado de manera circular. La castración es rechazada la homogenización globalizada, no existe salida porque no hay exterior posible. El exterior marca la negación de la identidad impuesta al sujeto por el discurso, recogiendo el pensamiento de Nietzsche (1887): "No existen hechos, existen interpretaciones", siendo la única interpretación la marcada por el poder de la razón capitalista. La posibilidad de un exterior marca el exilio de la imposición interpretativa del discurso: la imposibilidad del individuo de reafirmar su existencia en el existir del otro. Ese otro que se manifiesta en tanto ser en el discurso, negado en su individualidad e imposibilitado de una socialización marcada por su subjetividad. Esta es la gran dicotomía del individuo..., la búsqueda de un espacio en el afuera capitalista y su terror de un exterior que lo enfrenta a su propia falta en ser. El espacio social se conduce a una eterna permanencia en las esclusas de la ficción financiera del capitalismo, logrando un sentido de omnipotencia frente al devenir social.

El discurso y su negativa de vínculo social mantiene al individuo como un esclavo de la razón mercantilista, envolviendo al sujeto en su imperativo de goce. El poder de la razón capitalista pone límite a la pulsión del sujeto, transformando sus instituciones en herramientas destinadas a la imposición de una identidad cosificada. La razón capitalista rompe con la figura de la consciencia y la vigilancia frente al Yo, sumiendo al individuo en la falsa libertad del consumo sin límites, trasplantando al sujeto a una sociedad sin freno. El individuo acampa libre y sin restricciones en medio de la razón capitalista, explorando una y otra vez la utopía de la plenitud, un festín fraterno definido por Freud (1913), donde "el padre sacrificado por la horda"7 ha sido remplazado por los objetos, metáfora del rito al que los hijos concurren una y otra vez para consumir en una simulación antropofágica a un padre objeto..., si ayer los hijos mataron

$7 \quad$ La figura del padre de la horda primitiva se recoge de los desarrollos teóricos del texto de Sigmund Freud Tótem y Tabú (1913); allí se teoriza sobre la figura de un ser cuasi animal que se instala en un desarrollo precultural. Su muerte, a manos de sus hijos, y el posterior acto antropofágico desarrollado por ellos, sumado al pacto social y a las leyes exogámicas marcan el nacimiento de la cultura y la imposibilidad de emular la carencia de límites de aquella figura primitiva y ancestral. 
por el poder, las mujeres y la comida, hoy su voracidad apunta a la promesa de una plenitud utópica.

El individuo consume el objeto y su plenitud, rememorando a un padre que antaño poseyó un goce total y completo: si ayer recordábamos a ese padre muerto que poseía el goce total, hoy a través de la adquisición del objeto = plenitud recordamos el goce completo del padre sacrificado por los hermanos, instaurando un nuevo festín fraterno, el festín capitalista, el festín de la adquisición objetal. El objeto en la razón del discurso capitalista dificulta el encuentro con el propio deseo. El sujeto no reconoce su deseo individual, ya que es incapaz de articularlo a través de la propia palabra, dejándose llevar por la adquisición de objetos, eclipsando y desintegrando toda posibilidad de un saber individual, instaurando el objeto de consumo como elemento aglutinante del individuo, marcando el desarrollo de una razón capitalista sellada por la destrucción de todo vínculo social.

La comprensión del objeto se produce en una socialización a través del mismo objeto, es decir, en la plenitud que se asigna a dicho objeto. El individuo satisface su necesidad solapando su deseo, provocando una omisión de su saber y una dependencia a lo cósico. Esta nueva socialización a través del objeto nos confronta con la narrativa del discurso, la cual refuerza la idea del hombre nuevo, pleno y sin límites, alejado de su saber y marginado de su relación con los otros. El objeto y su acumulación entrega la ilusión de libertad, de plenitud y de certeza absoluta a expensas de nuestro deseo de saber, que a diferencia del objeto, nos enfrenta a nuestra falta estructural.

El avance de la razón capitalista nos enfrenta a cambios devastadores en la socialización del sujeto. El individuo del capitalismo no tiene información prohibida ni puertas cerradas: por la ventana abierta del objeto desfila un circo de saberes y significantes marcados por la existencia de una totalidad posible. El poder de la razón capitalista interrumpe el poder asociativo del sujeto. El individuo se muestra imposibilitado de crear un propio guión sobre el objeto ofertado por el discurso. El significado particular de cada uno de los objetos se desintegra en la conceptualización enmarcada por la razón capitalista. El significado del objeto consumo se sucede a través de una conexión estéril con el sujeto, todo su trabajo individual ha sido disuelto por la verdad oficial del discurso, no existiendo espacio para una participación subjetiva del individuo.

El sujeto en el océano de los objetos se sumerge en un tiempo marcado por un presente infinito. El tiempo en el discurso capitalista encuentra su sentido en el objeto, marcando la permanencia del individuo en la socialización capitalista. El sujeto consume el objeto negándose a entender el tiempo a partir de su propio tiempo. El tiempo es un efecto del discurso, enmarcado en la obtención de un objeto cuyo significado muestra la eternidad de un presente y la promesa de una plenitud. El sujeto en el discurso se encuentra fuera del tiempo, imposibilitado de ver su propia temporalidad. En el objeto puede verse lo que es el tiempo, un nuevo tiempo capitalista caracterizado por un presente permanente. 
El tiempo es uniforme en el discurso capitalista, su constitución homogénea no le permite ser medido, cobrando relieve solo en la adquisición del objeto. Todo antes y después se determina a través del ahora del objeto consumo, cuya imposición pasa por la multiplicidad de la oferta. Repensando la idea de Heidegger (1924) expuesta en su escrito El concepto del tiempo, el reloj, más que indicar el 'cuanto tiempo', en otras palabras, la cantidad de tiempo en su fluir presente, hoy consiste en fijar el aquí y el ahora de un consumo infinito, estructurado bajo el amparo de la socialización cosificada del discurso capitalista.

El sujeto, en el interior de la estructura discursiva del capitalismo se transforma en una existencia en el objeto. El objeto describe el mundo, dirigiendo al individuo a la imposibilidad de excluir al objeto y su peso simbólico. El individuo, su existencia y su estar frente a los otros pierde contacto con el mundo y su temporalidad. El individuo, bajo la estructura capitalista, se encuentra limitado en su posibilidad de ser. El sujeto en el presente perpetuo del discurso pierde su esencia, manifestación de un venir a la presencia que se encuentra en el conocer dinámico de la temporalidad ${ }^{8}$. El individuo en el interior de la temporalidad capitalista se muestra como un objeto del objeto mercancía, su relación con este ya no es de observación y contemplación, ahora su relación pasa por un significado incuestionable del objeto. El sujeto capitalista se encuentra marcado por la negación de su posibilidad de ser fuera del objeto, entregándose al dominio de una razón establecida por el discurso y su dialéctica del objeto consumo.

El estudio de la física entrega las herramientas para desarrollar un paralelo entre esta teorización y la actual situación. Einstein, en su texto Sobre la teoría de la relatividad espacial y general (1920), plantea algunas de las siguientes ideas: "El espacio no es nada en sí mismo", "No existe ningún espacio absoluto". "El espacio existe solo a través de los cuerpos y de las energías contenidas en él". El discurso capitalista gira las propuestas de la teoría de la relatividad, para platear que no existe espacio en sí mismo si no es a través del objeto de consumo. El espacio deja de existir a través de los cuerpos y energías contenidas en él, ahora existe solo a través del objeto único impuesto por la razón del discurso. El objeto solapa el deseo de saber del sujeto, remplazándolo por las respuestas engañosas (objeto = plenitud) que encontramos en él: no hay un tiempo absoluto, solo un objeto indiscutible.

El individuo, en el interior del discurso, al rechazar una temporalidad que albergue presente, pasado y futuro, rompe con su posibilidad de evolución y movimiento. El sujeto es atravesado por una falta. El individuo, en la negación de dicha falta, deja de ser sujeto, instalándose en la mentira de la totalidad. La temporalidad capitalista rompe con la existencia del individuo. La negación de su propia finitud dirige al sujeto a un existir en un presente continuo. El individuo capitalista avanza en el presente y hacia el presente. Este continuo temporal desvía al sujeto de su cuestionamiento vital, haciéndole olvidar su

8 El concepto de dinamismo temporal obedece a un desarrollo del tiempo que involucra presente, pasado y futuro, elementos estructurales que conectan el desarrollo del sujeto con la posibilidad de entendimiento de su propia existencia. 
falta estructural y su finitud como la posibilidad más extrema de sí mismo. La negación del pasado y el olvido del futuro rompe con el ser posible del sujeto, instalándolo en la realidad del objeto. El sujeto se cosifica en lo estático de un presente continuo, entregando el vínculo social a la posesión del objeto. El sujeto en la temporalidad capitalista rompe con su pasado y con la comprensión de este. El individuo ya no estuvo ahí entre esas o aquellas personas, entre esas palabras, entre esos recuerdos, entre esos que murieron. La relación del individuo con el presente capitalista se anuda en un arrastre de todo lo pasado hacia la inexistencia de lo que fue: "Este haber sido no es ningún 'qué', sino un 'cómo'; es el 'cómo' propio de mi existencia" (Heidegger, 2011, p. 45).

Memoria y temporalidad desde una perspectiva psicoanalítica nos dirigen a la génesis. Freud, desde Proyecto de una psicología para neurólogos (1895-1950, se refiere a la noción de codificado de los efectos placer/displacer. La teoría de las huellas mnémicas es imposible de comprender sin confrontar memoria y pulsión. La clínica psicoanalítica describe al paciente como quien sufre reminiscencias. El método catártico de Breuer permite al recuerdo actualizarse en la cura como reviviscencia masiva del pasado, es decir, la aparición en el campo de la consciencia de un afecto hasta entonces reprimido. Freud y su concepción de memoria inconsciente muestran el destino de una memoria que descarga sus puntos ciegos en la repetición.

Desde su lectura, Lacan nos enfrenta a una temporalidad marcada por importantes innovaciones. En 1945, su artículo "El tiempo lógico y el aserto de certidumbre anticipada. Un nuevo sofisma" establece tres tiempos que no son tres etapas cronológicas, por cuanto difieren unos y otros por su valor lógico: la instancia de la mirada, el tiempo para comprender y el momento para concluir. Cada uno de ellos es soportado por un sujeto diferente: el sujeto impersonal, el sujeto indefinido recíproco y el sujeto del aserto sobre sí mismo. Lacan plantea la palabra tiempo, entendida como una estructura, un estado sincrónico relativamente estable y no como un momento fugaz diacrónico. Las estructuras sincrónicas son una manera de explorar el enunciado de Freud sobre la inexistencia del tiempo en el inconsciente. Dicha atemporalidad marca la imagen de un deseo siempre presente, que no se ve afectado por el transcurso del tiempo, no obstante, Lacan modifica dicha concepción con su propuesta de 1964, desarrollada en El Seminario 11. Los cuatro conceptos fundamentales del psicoanálisis. Lacan plantea que el inconsciente es caracterizado en los términos de un movimiento temporal de apertura y cierre (relación de obturación), allí donde Freud situó el deseo Lacan establece la demanda y su repetición. El discurso capitalista a través de su negativa al cuestionamiento transgrede el tiempo del sujeto, protegiéndose no solo de la crítica sino también del momento para comprender. El discurso eliminando dicho momento se hace idéntico, transformándose en la repetición permanente de sí mismo.

La búsqueda del razonamiento adecuado y el razonar a tiempo se transforma en una instancia fundamental. El discurso capitalista genera en el individuo la imposibilidad de una verdad que anticipe el error del discurso. Su maquinaria 
funda un significante amo (S1) ${ }^{9}$. Un significante que representa al sujeto para todos los otros significantes. Este significante amo dirige al sujeto a la impostura de la plenitud (plenitud = objeto), censurando en el individuo toda posibilidad de un saber que no esté impuesto por la literatura capitalista.

La búsqueda incesante del objeto de consumo muestra al individuo en un estado permanente de repetición; lo sitúa en la dependencia de un tiempo extraño (presente permanente), rechazando la posibilidad de atravesar su fantasma, fijándolo en el centro de la temporalidad capitalista, encerrándolo en las esclusas de una petrificación, víctima de una sociedad momificada por un discurso enmarcado en el imperativo de goce.

Este falso equilibrio enraizado en el imperativo igoza! enfrenta al individuo con la negación institucionalizada de toda prohibición. La posibilidad de terminar con este modelo de socialización es castigado por la institucionalidad. La negación de los límites como pauta no verbalizada es asumida por el individuo, borrando de su existencia toda posibilidad de poner fin a esta estructura existencial. El injerto discursivo de la plenitud total se transforma en la negación del sujeto en tanto tal. El cuestionamiento y la crítica son arrancados del individuo, en su reemplazo el discurso capitalista instala una realidad que se equilibra entre la mentira y la fantasía.

Podemos ver claramente cómo la fantasía está del lado de la realidad, cómo soporta el "sentido de realidad" del sujeto: cuando el marco fantasmático se desintegra el sujeto sufre una "pérdida de realidad" y comienza a percibir la realidad como un universo "irreal" pesadillesco, sin una base ontológica firme; sino, por el contrario, es lo que queda de la realidad cuando esta pierde su apoyo en la fantasía. (Žižek, 2010, p. 30)

Lo real es la materialidad inventada y reinventada por la razón del discurso y su maquinaria capitalista. El pensamiento crítico, como acto irreductible de la realidad, es narcotizado por la materialidad cósica. Esta insensibilización vincular del sujeto apaga todo lazo social e interrogante existencial. La existencia del sujeto se entrega, a la imposibilidad de un cambio. El individuo se somete a una estructura que lo aleja de su existencia, instalándolo en un espiral de parálisis existencial: ya no existe un derecho al término, ni tan siquiera a la pausa, solo queda el continuismo en la petrificación: metáfora de una sociedad industrializada donde los individuos son piezas en una cadena a la espera del empaque final.

9 Lacan define el significante "como lo que representa a un sujeto para otro significante" en oposición al signo, que "representa algo para alguien" (Lacan, 2001, p. 207). Un significante que podemos denominar significante amo representará al sujeto para todos los otros significantes. Lacan, cuando se refiere a los significantes, a menudo se refiere a lo que otros denominarían palabras, pero estos términos no son equivalentes: "también pueden funcionar como significantes unidades de lenguaje más pequeñas que las palabras (morfemas y fonemas) o más grandes que las palabras (frases y oraciones), y pueden desarrollarlos entes no lingüísticos, por ejemplo objetos, relaciones y actos sintomáticos" (Evans, $2010,177)$. La única condición que caracteriza a algo como significante es, para Lacan, que esté inscrito en un sistema en el que adquiere valor de manera exclusiva en virtud de su diferencia con los otros elementos del sistema. 
El discurso capitalista nos enfrenta a la institucionalización del goce y a la ruptura de todo vínculo social, creando una dependencia hacia el objeto y su realidad construida. Toda socialización se vuelve soledad en tanto se enmarca en el filtro exterior de lo cósico, como lo señala Cioran: "Aislados, separados del mundo, todo se nos vuelve inaccesible. La muerte más profunda, la verdadera muerte, es la muerte causada por la soledad, cuando hasta la luz se convierte en un principio de muerte" (1991, p. 30).

El individuo se transforma en una máquina funcional que rechaza toda socialización, su búsqueda se centra en la oferta de plenitud instaurada por el discurso: una demanda que rechaza todo vínculo que no esté mediado por la materialidad instaurada por el discurso. El saber del sujeto en tanto articulación de los significantes en el universo simbólico se entrega a la repetición de un significante amo impuesto por el discurso (objeto=plenitud). El inconsciente no es más que otro nombre del saber simbólico, constituye un saber desconocido, un saber que el sujeto no sabe que tiene. Este saber es el que desconocemos y entregamos al olvido.

Estamos presos en la falta de saber, el acceder a más saber nos da la posibilidad de un goce mejor, un acuerdo entre el goce y su fin. El misterio del saber no es personificado por el inconsciente: "para el saber que habla el saber es lo que se articula, [...] nada es en la medida en que eso se dice que es" (Lacan, 2008, p. 166). El saber simbólico es saber de la verdad sobre el propio deseo inconsciente. El saber es una forma de goce: "El saber es el goce del Otro" (Lacan, 2009, p. 13). El saber simbólico no habita en un sujeto particular ni en el Otro (que no es un sujeto sino un lugar), es intersubjetivo.

Este saber simbólico es trasladado al objeto consumo en el discurso capitalista. El objeto evacúa la duda en el sujeto, ese saber intersubjetivo habita en el objeto. El individuo, cuando adquiere productos ofertados por el discurso adquiere saber, un saber capitalista mediado por su rápido desecho y constante puesta en marcha. El discurso capitalista entrega una falsa plenitud a través de la adquisición de ese 'objeto faltante', el cual se representa en los múltiples objetos ofertados y entregados por el discurso. Estos objetos encierran al sujeto en una falsa plenitud que lo dirige a la utopía de la totalidad.

El discurso capitalista permite el avance del sujeto hacia una búsqueda y adquisición infinita de objetos. El consumo como medio de socialización es un rechazo a la posibilidad de saber sobre aquel objeto que no está y que no estará jamás. El objeto como necesidad autocreada y repetida por el discurso es una negación al medio saber del sujeto del inconsciente. El discurso capitalista encierra al sujeto en un círculo de silencio, condenándolo a una búsqueda permanente del objeto consumo, vaciándolo de todo contenido, sumiéndolo en el mutismo más completo. La relación con sus iguales se vuelve opaca. El individuo desaparece como global y social, su globalidad se reduce a la búsqueda y obtención del objeto consumo. El sujeto se disuelve en lo más profundo de su no ser, mientras el discurso capitalista nos entrega al objeto disfrazado de totalidad, este 
entrega la respuesta y la reafirmación de la existencia al individuo. El objeto uniforma, logrando la reafirmación del individuo en tanto la adquisición del objeto ofertado.

La consigna capitalista nos invita a un mundo carente de restricciones, cuyas respuestas se simbolizan en el objeto consumo, somos iguales en la transgresión, vivimos en el imperativo buscando las respuestas en el objeto. El objeto marca el anclaje del individuo a la existencia en el discurso, el cordón umbilical por el que el discurso capitalista alimenta al individuo en el espejismo de un sujeto sin falta, aquel elemento constitutivo del sujeto se diluye en el discurso capitalista, el ser ya no interroga a su ser, ahora interroga al objeto. El existir ya no implica el acceso al medio saber analítico. El saber del sujeto del inconsciente es hoy el saber del objeto. El objeto se transforma en el adulto que escucha el grito del niño y lo transforma en llamada. El infante encuentra en ese Otro ${ }^{10}$ protección y alimento, mientras el individuo contemporáneo recoge del objeto consumo la respuesta a su llamada. El discurso capitalista propone que esa llamada sea reconocida a través del objeto. El discurso esconde la falta utilizando al objeto mercancía como cierre forzado de un espacio faltante en el sujeto. El objeto mira. Los individuos son mirados por los objetos, su mirada atrae al sujeto como la voz de la madre atrae al infante. El objeto envuelve al sujeto como el niño se deja envolver por la calidez de ese Otro que lo alimenta y protege. El objeto alimenta, observa y protege al individuo; si ayer ese Otro materno escuchó los gritos del individuo, hoy el individuo escucha las respuestas del objeto.

El psicoanálisis transporta esta idea filosófica y nos confronta con la figura del cuerpo del niño del que emana el grito, el cual, como consecuencia de la asistencia ajena, siempre quedará relacionada con la imagen del objeto que ha calmado su excitación: "la que Freud concibe como la primera mítica vivencia de satisfacción. El deseo, dirá Freud, será el residuo de esa satisfactoria vivencia" (Gallano, 2010, p. 13).

El discurso capitalista es pérdida de memoria, ya que niega la falta del sujeto en su recuerdo de satisfacción. El deseo es impulso que desde la carencia encuentra su camino en la realidad. Esta verdad analítica es violentada y alterada por el discurso capitalista, ese impulso ya no encuentra su camino en la realidad, ahora su camino está dirigido hacia los objetos, son estos los catalizadores del deseo del sujeto, satisfacción rápida y desecho instantáneo, respuestas fáciles que distraen, condicionan y conducen el deseo del individuo. El deseo encontrado por Freud en la insistencia del inconsciente tiene su paralelo en la filosofía de Spinoza (1677), con su concepto de la esencia del hombre. Spinoza desarrolla este concepto en tanto la esencia de las cosas es ese esfuerzo sin el cual las cosas no serían. Freud, desde el psicoanálisis, y Spinoza, desde la filosofía, nos confrontan

10 La conceptualización de ese gran Otro se desarrolla en la enseñanza de Jacques Lacan como la alteridad radical, "la otredad que trasciende, la otredad ilusoria de lo imaginario, porque no puede asimilarse mediante la identificación" (Evans, 2010, p. 143). Lacan equipara esta alteridad radical con el lenguaje y la ley, ya que el Otro está inscrito en el orden simbólico. En resumen, el Otro será otro sujeto en su alteridad radical, en su singularidad inasimilable y en el orden simbólico con ese otro sujeto. El pequeño otro, a su vez, es el otro que no es realmente otro, sino un reflejo y proyección del Yo; de manera simultánea, es el semejante y la imagen especular. 
con una fuerza rectora que dirige al sujeto en un caso y que permite que las cosas sean en el otro.

Platón (380 a. C.) señaló en su obra El Banquete: “Lo que desea, desea algo de que está falto, y no lo desea si está provisto de ello" (2004, p. 49). La afirmación platónica resulta una media verdad en la era del discurso capitalista, quien está provisto del objeto no está alejado del deseo insaciable de seguir deseando, es la tenencia del objeto y su breve satisfacción lo que impulsa al individuo a una conducta repetitiva de adquisición del objeto consumo, nunca se tiene suficiente. El objeto es el placebo de una pregunta sin respuesta, un círculo semicerrado en un espacio marcado por el olvido de la falta estructural.

El objeto, desde una perspectiva filosófica absorbe en su significado capitalista la falsa calma del individuo. La falta del sujeto lacaniano permanece latente, rodeado y solapado por 'figuras materiales' que obstaculizan pero no eliminan su falta en ser. El acto de poseer sin medida ni límite dirige al individuo al letargo de la temporalidad capitalista, recogiendo lo expresado por Martin Heidegger: "Ante el azul el rostro del animal se retira a la ternura. Pues la ternura es, al pie de la letra, lo pacíficamente recogedor. Transforma la discordia absorbiendo lo lesivo y abrazador de lo selvático en el dolor apaciguado" (Heidegger, 1987, p. 42). El individuo invoca al objeto cuan si fuera un oráculo en vías de predecir su destino. El individuo se cobija en su falta de saber, arremetiendo con violencia hacia todo cuestionamiento, exiliando de sí todo vestigio de duda y pregunta.

El discurso capitalista, con el nombre de objeto consumo, invoca aquella falta desarrollada por Lacan: dejamos de pensar en los pasos del Otro ya que estos han sido solapados por la sombra de la plenitud objetal. La razón capitalista crea un nuevo individuo alejado de la posmodernidad, un ser extraviado que busca una vida alejada de su falta, enclaustrado en la utopía de la plenitud. La plenitud capitalista no es una abstracción del discurso, su materialización es el objeto, su figura se transforma en lo sagrado, en el camino 'racional' hacia un saber total y completo.

El individuo se transforma en una figura abandonada a la dictadura del objeto, el saber no se encuentra en el sujeto del inconsciente, sino en el objeto entregado a la conceptualización capitalista. La falta en medio de este olvido reaparece una y otra vez. El discurso cierra filas en la producción y entrega de objetos sin límite, mientras el sujeto faltante se hunde en el desconocimiento de su propia falta.

El saber desoído es la esencia del objeto. Este rechazo marca 'algo' de verdad de la necesidad del individuo. El individuo necesita saber, saber sobre su deseo y su falta. Las preguntas son transformadas por la estructura del discurso, ofreciendo una respuesta única, cosificada y totalizadora. El sujeto se descompone abandonándose al sin sentido del espiral del consumo. El individuo traslada su deseo de saber a un objeto que entrega certezas no dudas. El sujeto se hunde en un falso saber, con un objeto que antaño cubrió sus necesidades y que hoy promete una falsa plenitud en el desconocimiento de su falta. 
El discurso oculta la vía regia del cuestionamiento y la duda, abriendo paso a la promesa de una acumulación sin límites. El individuo se consume en una estructura capitalista anclada en el objeto. El inconsciente es negado y oscurecido, su esencia 'selvática' es falsamente domesticada, dirigida hacia su negación. El discurso capitalista ilumina su objeto, frente a su resplandor el sujeto ensombrece, enfriándose hasta la petrificación. La carencia del objeto para el individuo capitalista $^{11}$ se transforma en oscuridad y exilio social. El objeto atraviesa de manera transversal la vida del sujeto envolviéndolo todo con su falsa plenitud.

"Cuando los mortales siguen a 'algo extraño' llamado al declive, es decir, cuando andan tras el extraño, acceden ellos mismos a la extrañez; devienen extraños y solitarios" (Heidegger, 1987, p. 46). El individuo capitalista camina ausente de su entorno, separado de los otros. El sujeto, en su individualidad, es moldeado por la imagen del nuevo hombre capitalista, asfixiado en una socialización mediada por los objetos.

Por ahora, la tecnificación hace a los gestos precisos y adustos, y, con ellos, a los hombres. Desaloja de los ademanes toda demora, todo cuidado, toda civilidad para subordinarlos a las exigencias implacables y como ahistóricas de las cosas. Así, pongamos por caso, llega a olvidarse cómo cerrar una puerta de forma suave, cuidadosa y completa. Las de los automóviles y neveras hay que cerrarlas de golpe; otras tienen la tendencia a cerrarse solas, habituando así a los que entran a la indelicadeza de no mirar detrás de sí, de no fijarse en el interior de la casa que los recibe. (Adorno, 2006, p. 44).

Este camino arrastra al sujeto a la negación de su singularidad, somos un colectivo individualizado en nuestro devenir social, hemos transformado nuestro ser enclaustrándolo en la nueva socialización capitalista, en la simple y llana adquisición. La socialización capitalista reduce los espacios a las instancias de consumo. El sujeto es incapaz de romper este círculo hermético, consume pero no socializa. El otro es un rival, una amenaza en la búsqueda de la respuesta entregada por el objeto. El objeto es el oráculo del hombre posmoderno. El individuo no lucha por el objeto, pelea por las respuestas que este le entrega. El discurso capitalista iguala al individuo en su sed de consumo pero lo individualiza en su posibilidad de adquisición de objetos. Este punto es fundamental para lograr un adormecimiento del entramado social, mientras algunos individuos consumen sin límites viviendo en el imperativo, otros luchan por llegar a un imperativo que suponga la extinción de todo límite y el encuentro con la respuesta prometida por el objeto. El discurso capitalista supera la era de la razón, su proyección en el logos y su separación de la realidad existencial del sujeto se transforma en una entronización del objeto consumo, dejando de lado todo espacio para la urgencia del pensar filosófico y el saber analítico.

11 El autor del presente artículo hace referencia al individuo capitalista como un sujeto depositario del lazo social que se desarrolla en el interior del discurso. 
Heidegger (1950-1959) planteó que el individuo es hablado por el lenguaje, mientras Lacan instauró que el inconsciente se estructura como un lenguaje. El actual discurso nos instala en el ser hablados por el objeto consumo. El individuo es en tanto consume, el acto de consumir proporciona al sujeto un espacio completo y sin restricciones. La negación de esa falta estructural hoy se reafirma en la materialidad del objeto, ese objeto que tapona nuestra falta y entrega las respuestas de una nueva socialización capitalista basada en el imperativo. El sujeto intenta colmar el vacío que genera su falta, creando una producción ilimitada de objetos que reducen al sujeto al consumo de materias primas.

El orden político y social fuera del discurso se quiebra y se diluye, el poder y el desarrollo del porvenir ciudadano se entrega al objeto. Este objeto y su deseo de adquisición actúa sobre la voluntad y la capacidad crítica del individuo. Toda conducta de las instituciones regidas por el discurso capitalista incluye algún grado de distribución del imperativo, y esta promesa de una vida en el goce es la esencia de la política del actual discurso. El objeto es la autoridad en la que se instituye el saber del individuo, este rango distingue a las instituciones políticas que nacen como la metástasis del discurso capitalista. Una democracia totalitaria resulta de la situación actual. La vida privada y pública pierde toda posibilidad de separación, tanto una como otra se ven invadidas por el discurso.

\section{Referencias}

Adorno, T. (2006). Minima moralia. Madrid: Akal.

Adorno, T. (2008). Crítica de la cultura y sociedad (vol. 1). Madrid: Akal.

Cioran, E. (1991). Las cimas de la desesperación. Barcelona: Tusquets.

Einstein, A. (2012). Sobre la teoría de la relatividad espacial y general. Madrid: Alianza.

Evans, D. (2010). Diccionario introductorio de psicoanálisis lacaniano. Buenos Aires: Paidós Lexicon.

Freud, S. (2006). Proyecto de psicología (vol. 1). Buenos Aires: Amorrortu.

Freud, S. (2001). Tótem y tabú (vol. 13). Buenos Aires: Amorrortu.

Freud, S. (2010). Más allá del principio del placer (vol. 18). Buenos Aires: Amorrortu.

Freud, S. (2000). Duelo y melancolía (vol. 14). Buenos Aires: Amorrortu.

Foucault, M. (2015). Historia de la locura en la época clásica. Madrid: Fondo de Cultura Económica de España.

Gallano, C. (2010). El Deseo: textos y conferencias. Madrid: Colegio de psicoanalistas de Madrid. 
Heidegger, M. (1987). De camino al habla. Barcelona: Ediciones del Serval.

Heidegger, M. (1999). El concepto del tiempo. Madrid: Minima Trotta.

Korman, V. (2004). El espacio psicoanalítico: Freud-Lacan-Möbius. Madrid: Síntesis.

Lacan, J. (2008). El seminario XX. Buenos Aires: Paidós.

Lacan, J. (2009). El seminario XVII. Buenos Aires: Paidós.

Lacan, J. (2001). El seminario XI. Buenos Aires: Paidós.

Lacan, J. (2001). El seminario XI. Barcelona: Paidós.

Lacan, J. (2007). Del sujeto por fin cuestionado. En Escritos (vol 1). Madrid: Siglo XXI.

Lacan, J. (1984). El tiempo lógico y el aserto de certidumbre anticipada. Un nuevo sofisma. Los escritos (vol 1). México, D. F.: Siglo XXI.

Mumfor, L. (2013). El mito de la máquina: técnica y evolución humana. La Rioja: Pepitas de Calabaza.

Nietzsche, F. (2010). La genealogía de la moral. Madrid: Tecnos.

Platón. (2004). El banquete. Madrid: Tecnos. Colección clásicos del pensamiento (2004).

Soler, C. (2007). Discurso capitalista. En Los discursos de Lacan. Madrid: Colegio de Psicoanálisis de Madrid.

Spinoza, B. (2014).Tratado de la reforma del entendimiento. Madrid: Alianza.

Stavrakakis, Y. (2007). El objeto lacaniano. En Lacan y lo político. Buenos Aires: Prometeo libros.

Žižek, S. (2010). El acoso de las fantasías. Madrid: Siglo XXI. 